\title{
Effects of Solvent Etching on PMMA Microstructured Optical Fiber Bragg Grating
}

\author{
Janting, Jakob; Pedersen, Jens; Inglev, Rune; Woyessa, Getinet; Nielsen, Kristian; Bang, Ole
}

Published in:

Journal of Lightwave Technology

Link to article, DOI:

10.1109/JLT.2019.2902244

Publication date:

2019

Document Version

Peer reviewed version

Link back to DTU Orbit

Citation (APA):

Janting, J., Pedersen, J., Inglev, R., Woyessa, G., Nielsen, K., \& Bang, O. (2019). Effects of Solvent Etching on PMMA Microstructured Optical Fiber Bragg Grating. Journal of Lightwave Technology, 37(18), 4469 - 4479. https://doi.org/10.1109/JLT.2019.2902244

\section{General rights}

Copyright and moral rights for the publications made accessible in the public portal are retained by the authors and/or other copyright owners and it is a condition of accessing publications that users recognise and abide by the legal requirements associated with these rights.

- Users may download and print one copy of any publication from the public portal for the purpose of private study or research.

- You may not further distribute the material or use it for any profit-making activity or commercial gain

- You may freely distribute the URL identifying the publication in the public portal 


\title{
Effects of Solvent Etching on PMMA Microstructured Optical Fiber Bragg Grating
}

\author{
Jakob Janting, Member, OSA, Jens K. M. Pedersen, Rune Inglev, Member, OSA, Getinet Woyessa, Kristian \\ Nielsen, and Ole Bang, Life Fellow, OSA
}

\begin{abstract}
Polymer Optical Fiber Bragg Gratings (POFBGs) can be solvent etched to achieve higher sensitivity sensors. To analyze the influence of etch on the mechanical and thermal performance of PMMA based microstructured POFBGs (mPOFBGs), we etched annealed and unannealed samples in pure acetone, while at the same time monitoring the induced Bragg wavelength shifts. Optical-thermodynamical interpretation of these shifts together with thermal and mechanical testing of etched fibers, reveal that solvent etching can lead to trapping of residual plasticizing solvent in the polymer matrix and consequently to change of Young's modulus and thermal instability of the etched mPOFBG. Removal of these solvent residuals by thermal treatment results in a stable linear response with a thermal sensitivity indistinguishable of that of the unetched mPOFBG. The maximum found change of Young's modulus due to acetone plasticization during etch is $\sim 5 \%$ for both unannealed and annealed mPOFBGs. The mPOFBG force sensitivity increases greatly with reduced diameter and the relatively small changes in strain sensitivity and Young's modulus introduced by the etching process in this case do not have a big effect.
\end{abstract}

Index Terms-Fiber optics, Fiber Bragg gratings, Optical polymers, Etching, Optical sensors.

\section{INTRODUCTION}

$\mathbf{F}$ IBER Bragg gratings (FBGs) inscribed in polymer optical fibers (POFs) is a promising technology for a wide range of sensing applications [1]-[3]. They respond to external stimuli by shift in the reflected Bragg wave length $\lambda_{B}$ according to eq. (1), where $n_{e f f}$ is the effective refractive index of the fiber at the FBG location and $\Lambda$ is the periodicity of the grating.

$$
\lambda_{B}=2 n_{e f f} \Lambda
$$

Compared with FBGs inscribed in conventional silica optical fibers, polymer optical fiber Bragg gratings (POFBGs) additionally offer several interesting properties such as increased sensitivity to axial stress due to the low Young's modulus $E$ of polymers and increased strain sensing range due to the high elastic limit. This can be seen from eq. (2) showing the $\lambda_{B}$ shift, $\Delta \lambda_{B}$, of a POFBG with cross sectional area $A$ in response to an applied axial force $F$.

$$
\Delta \lambda_{B}=\lambda_{B}\left(1-P_{\varepsilon}\right) \frac{F}{E A}=\frac{S_{\varepsilon}}{E A} F
$$

Manuscript received.....

J. Janting, R. Inglev, G. Woyessa and O. Bang are with DTU Fotonik, Department of Photonics Engineering, Technical University of Denmark, 2800 Kongens Lyngby, Denmark (e-mails: jajant@ fotonik.dtu.dk, ruing@fotonik.dtu.dk, gewoy@ fotonik.dtu.dk, oban@fotonik.dtu.dk)

J. K. M. Pedersen is with OFS Fitel Denmark ApS, Priorparken 680, 2605 Brøndbyvester, Denmark (e-mail: jmp@jmpconsult.dk)

K. Nielsen and O. Bang are with SHUTE Sensing Solutions A/S, Oldenvej 1A, 3490 Kvistgård, Denmark (e-mails: kn@shute.dk, oban@fotonik.dtu.dk)
$S_{\varepsilon}=\lambda_{B}\left(1-P_{\varepsilon}\right)$, where $P_{\varepsilon}$ is the strain-optic or photoelastic coefficient, is the strain sensitivity of the FBG depending on changes in $\Lambda$ and $n_{\text {eff }}$ when the fiber is stretched [4]. In several applications, it is of interest to further increase the sensitivity of FBGs to tensile forces, i.e. decrease the amount of axial force needed to produce a certain value of strain. For instance, this is highly useful when using the FBG in combination with a transducer for chemical sensing and biosensing applications [5]-[8]. This can be achieved by reducing $A$ in eq. (2). One way of doing so is by chemical etching, which has the advantage that it can be precisely controlled and is easily scalable [9]. Etching of PMMA-based POFs using acetone or acetone/methanol mixtures has previously been reported [10]-[14]. Rajan et al. [10] etched a PMMA-based POFBG humidity sensor using an acetone/methanol mixture to decrease the response time of the sensor. Together, Bhowmik et al. [14], Leal-Junior et al., [15] and Pospori et al. [16] have demonstrated that annealing and reduction of the PMMA fiber diameter by etching with acetone or a acetone/methanol mixture results in a reduced Young's modulus and increased sensitivity towards strain, stress, force, temperature and pressure. The process of annealing in order to release residual stress of POFs has previously been demonstrated to be of great importance in ensuring stable sensing properties without hysteresis [17], [18]. Fasano et al. [19] demonstrated, that mixtures of methanol and water could be used to introduce stress relaxation of drawn POFs. In this paper, we present in greater detail, the effects of solvent etching on the thermo-mechanical properties of microstructured polymer optical fibers (mPOFs).

\section{THEORY, EXPERIMENTS AND RESULTS}

\section{A. PMMA etching}

Using Hansen Solubility Parameter (HSP) theory [20], it can be shown how well different solvents are able to etch thermoplastic polymers like PMMA. The polymer solubility is determined by the ratio of two distances in the threedimensional HSP space. The coordinates of solvents and polymers in this "solubility space" are Dispersive $\left(\delta_{D}\right)$, Polar $\left(\delta_{P}\right)$ and Hydrogen bonding $\left(\delta_{H}\right)$ cohesive energy density parameters like those given in Table I, where the values for the PMMA grade $\left(\right.$ GEHR PMMA ${ }^{\circledR}$ ) used here have been determined experimentally from unannealed cane pieces. The other listed solvent HSP and molecular volume $(\mathrm{MVol})$ values are from the database included in the Hansen Solubility Parameters in Practice (HSPiP) software version 5.0.09. The HSP unit is $\sqrt{\mathrm{MPa}}$ or sometimes $\sqrt{\mathrm{J} \cdot \mathrm{cm}^{-3}}=0.49 \cdot \sqrt{\mathrm{cal} \cdot \mathrm{cm}^{-3}}$. The 
TABLE I

HSP, $R_{0}, M V o l$ VALUES AND $R E D$ NUMBERS FOR PMMA AND SOME PMMA ETCHING AND SWELLING SOLVENTS

\begin{tabular}{c|cccccc}
\hline \hline Material & $\delta_{D}$ & $\delta_{P}$ & $\delta_{H}$ & $R_{0}$ & $M V o l$ & $R E D$ \\
\hline PMMA & 18.7 & 8.6 & 8.9 & 6.7 & NA & NA \\
Acetone & 15.5 & 10.4 & 7 & NA & 73.8 & 0.97 \\
Trichloroethylene & 18 & 3.1 & 5.3 & NA & 90.1 & 0.98 \\
Chloroform & 17.8 & 3.1 & 5.7 & NA & 80.5 & 0.89 \\
Methanol (cluster) & 14.7 & 5 & 10 & NA & 100 & 1.36 \\
Acetone/methanol 50/50 v/v\% & 15.1 & 7.7 & 8.5 & NA & NA & 1,08 \\
\hline
\end{tabular}

$M V o l$ unit is $\frac{\mathrm{cm}^{3}}{\text { mole }}$. The ratio of the distance between polymer and solvent in HSP space $\left(R_{a}\right)$, to that of the interaction radius $\left(R_{0}\right)$ of the polymer (also determined experimentally), the Relative Energy Difference $(R E D)$ number, tells how well a solvent dissolves the polymer. $R E D$ below 1 means that the HSPs for polymer and solvent are all sufficiently similar for the polymer to be dissolved by the solvent cf. the rule of thumb "like dissolves like" [20]. The smaller the $R E D$ value, the better the solvent is for dissolving the polymer. For $R E D \approx 1$ the polymer swells. Far away from the polymers solubility sphere determined by $R_{0}, R E D \gg 1$ and the solvents here do not affect the polymer. It is important to note, that it depends on the polymer and solvent how far away from $R E D=1$ dissolution or no interaction is observed.

HSPs and $R_{0}$ for a polymer depend strongly on the specific grade and treatment history. They are determined by testing the polymer in different solvents and fitting a solubility sphere to the observed dissolution, swelling and no interaction data. Important test parameters determining the HSP, $R_{0}$ and hence $R E D$ number accuracies are e.g. the number of test solvents close to the solubility sphere and the temperature stability. The test procedures for solvent POF etching using HSP theory have been described elsewhere in more detail by Inglev et al. [21] and Hassan et al. [9].

In our case of unannealed PMMA POF etching, swelling takes place relatively close to $R E D=1$. Acetone is not a particularly good solvent, as it has a $R E D$ of 0.97 , however, since etching of a polymer fiber is actually a "controlled dissolution", good etching solvents are expected to be somewhat bad solvents, such that the outer layers of the polymer are "slowly" removed. For the etch to be slow, a relatively large $\mathrm{MVol}$ is also an important parameter, because large volume means slower diffusion into the polymer [20]. Trichloroethylene has different $\delta_{D}, \delta_{P}$ and $\delta_{H}$ values but is still a candidate for PMMA etching, since it has comparable RED and $M V o l$ values to that of acetone, see Table I. Experiments also show that trichloroethylene works well as an etching solvent. Chloroform is another solvent which dissolves PMMA well, but because it has both lower $R E D$ and $M V o l$ values, experiments confirm that it is difficult to produce a controlled POF etch. The $R E D$ and $M V o l$ values for methanol also clearly confirm that this solvent which is widely used for etching, when mixed with acetone, and doping of POFs, only swells the polymer. HSPs are additive and by mixing acetone with e.g. methanol it is possible slow down the etch by getting HSPs closer to but still below $R_{0}$ for a specific PMMA grade of interest [10][14], [22]-[25]. However, for our PMMA POFs (unannealed), there is no need to slow down the acetone etch and increasing the $R E D$ just a little from 0.97 (acetone etchant), to 1.08 by instead utilizing the common $50 / 50 \mathrm{v} / \mathrm{v} \%$ acetone/methanol mixture, gives crazing (microscopic cracks in the surface) in addition to slow etching. We believe this is probably also to some extent due to clustering properties of methanol. It should also be mentioned that we still observe this effect for annealed PMMA POFs, even though this treatment leads to residual stress relaxation and $R_{0}$ lowering, and is known to reduce the risk of Environmental Stress Cracking (ESC) and crazing [20].

\section{B. PMMA sorption and desorption of acetone}

Originally, this work was initiated by a suspicion that solvent sorption could lead to long term plasticization and therefore influence on etched PMMA based POFBG performance. This was based on earlier observed pronounced long term plasticization when etching low $T_{g}\left(78^{\circ} \mathrm{C}\right)$ TOPAS POFs with cyclohexane. This softening could contribute to the explanations by Bhowmik et al. [14] why they observe that Young's modulus of PMMA based POFs are lowered by etching.

In order to estimate the amount of residual acetone left in the material during the etching process, a $0.6851 \mathrm{~g}$ piece of PMMA fiber cane (of the same PMMA-grade as the mPOF used in this work) was placed in a petri dish, weighed on a high precision scale $(0.1 \mathrm{mg}$ resolution) and placed in saturated acetone vapor. The weight increase was then monitored at different times during the acetone sorption process. The PMMA piece was exposed to the solvent vapor instead of liquid because small drops of liquid on the sample surface are difficult to get off before weighing. Besides, exposure to saturated vapor, i.e. a Relative Humidity $(R H)$ of $100 \%$, corresponds to liquid exposure like during etching cf. equation (3), where $a_{s}^{v}$ and $a_{s}^{l}$ are the solvent's $(s)$ activities in the vapor $(v)$ and liquid $(l)$ phases respectively.

$$
R H=a_{s}^{v} 100 \%=100 \% \Leftrightarrow a_{s}^{v}=1=a_{s}^{l}
$$

PMMA cannot be saturated with acetone because $R E D<1$ i.e. PMMA is dissolved and equation (4), where $\mu_{s}^{l}, \mu_{s}^{v}, \mu_{s}^{p}$ are the chemical potentials of the solvent in the liquid $(l)$, vapor $(v)$ and polymer $(p)$ phases, will hold as long as liquid solvent is available to maintain a saturated vapor around the polymer.

$$
\mu_{s}^{l}>\mu_{s}^{v}>\mu_{s}^{p}
$$

After five days, the petri dish containing the cane piece was moved to room conditions (fume hood). At this time the shape of the piece had changed completely to a flat, round puddle at the bottom of the petri dish. The weight change was repeatedly monitored during desorption. The results are shown in Fig. 1. The desorption was fast in the beginning where most of the sorbed acetone was diffusing out of the structure, but then slowed down. After 35 days there was still more than $6 \mathrm{wt} \%$ acetone left in the PMMA. The petri dish containing the PMMA piece was then moved from room conditions to 


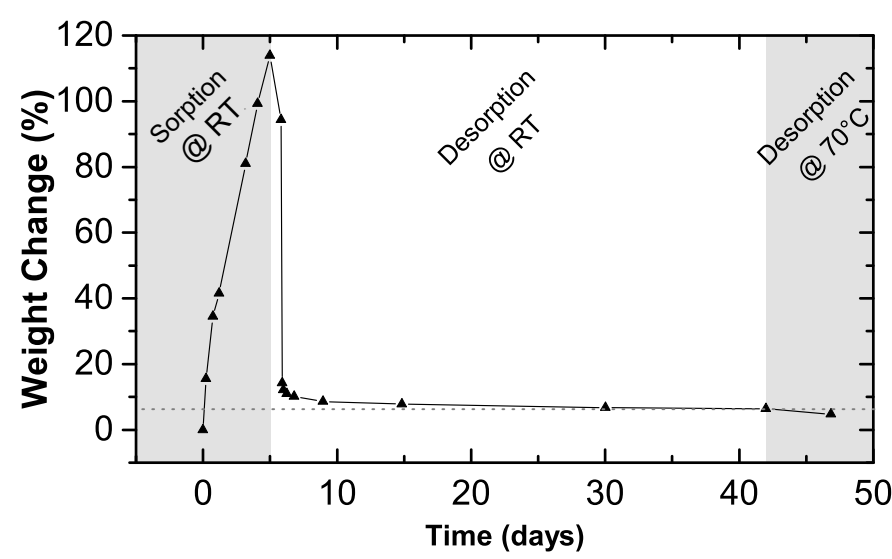

Fig. 1. Weight change related to the sorption and desorption of acetone vapor in a PMMA-cane piece. After 40 days there is still $4.8 \mathrm{wt} \%$ acetone present inside the PMMA.

an oven at $70^{\circ} \mathrm{C}$ for an additional five days, after which the acetone content had dropped to $4.8 \mathrm{wt} \%$. This indicates, that it may be quite difficult to get all the acetone out of the structure, i.e. another way of expressing the earlier mentioned rule of thumb is: like tends to stay inside like.

\section{FBG fabrication}

The POF used in this work was a microstructured, 2-ring PMMA fiber fabricated in-house using the drill-and-draw method, see Fig. 2. It has an average diameter of $150 \mu \mathrm{m}$ with hole diameters of $2 \mu \mathrm{m}$ and a hole-to-pitch ratio of 0.40 making it endlessly single mode [26].

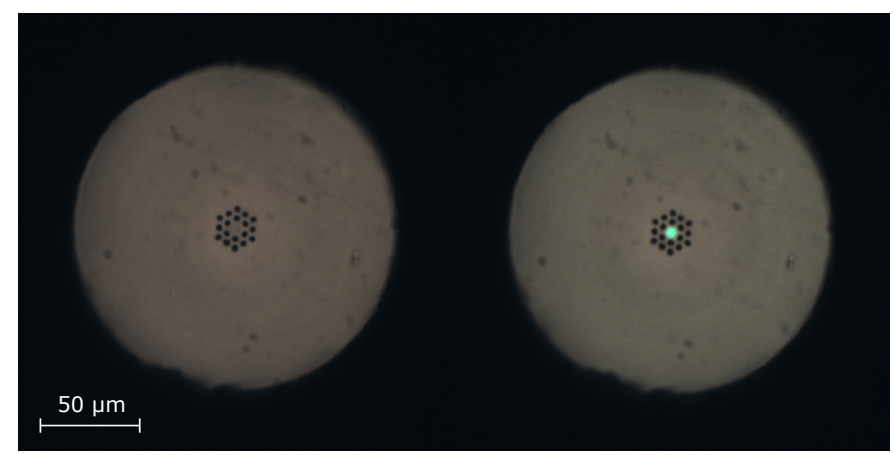

Fig. 2. Fiber profile of a PMMA mPOF with a 2-ring cladding structure. The fiber was cut at $77.5{ }^{\circ} \mathrm{C}$ using the method described by Stefani et al. [27]. Right: Light from an LED coupled into the fiber, showing how the light is confined to the core region.

10 pieces of $\mathrm{mPOF}(40 \mathrm{~cm}$ each) from the same draw were used for grating inscription. 5 of the pieces were used as is. To study the influence of annealing on $\mathrm{mPOFBG}$ etching, the remaining 5 pieces were annealed in water at $65^{\circ} \mathrm{C}$ for 5 days. This process releases residual stress originating from the drawing process, ensuring thermal stability of the grating below the annealing temperature [18].

The FBGs with $\lambda_{B} \approx 850 \mathrm{~nm}$ were inscribed using the phase mask technique [2], [28], see the setup in Fig. 3. A $325 \mathrm{~nm} \mathrm{CW} \mathrm{HeCd} \mathrm{UV-laser} \mathrm{(IK5751I-G,} \mathrm{Kimmon)} \mathrm{with}$ the output power attenuated to $18 \mathrm{~mW}$ was focused using a

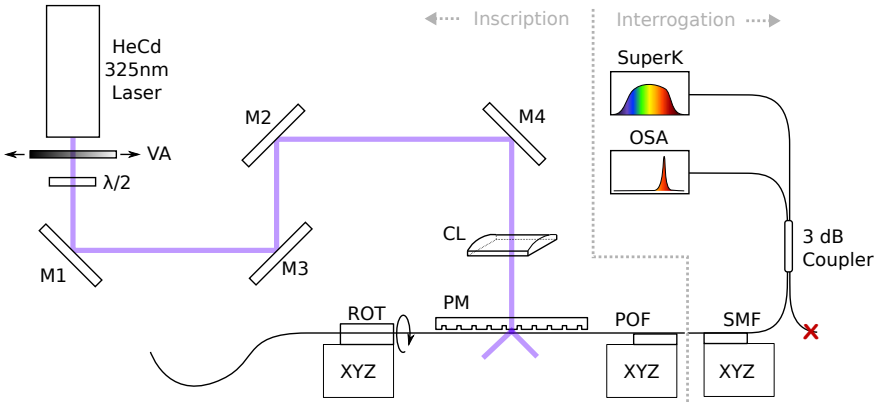

Fig. 3. POFBG inscription setup. VA: Variable attenuator. CL: Cylindrical lens. PM: Phase mask. ROT: Rotatable fiber clamp. POF: Polymer optical fiber under inscription. SMF: Silica single mode fiber pigtail.

cylindrical lens through a phase mask with a grating pitch of $572.4 \mathrm{~nm}$ (Ibsen Photonics A/S) on the optical fiber while monitoring the peak growth using a reflection mode interrogation setup. Each FBG was inscribed in less than 7 minutes using this technique [29]. It should be mentioned, that using a pulsed $\mathrm{KrF}$ laser, FBGs in POFs can be inscribed in less than 30 seconds [30], [31]. The interrogation setup consisted of a supercontinuum laser (SuperK Versa, NKT Photonics A/S) launched into one of the arms of a $3 \mathrm{~dB}$ coupler (TW850R5A2, Thorlabs). One output arm was buttcoupled to the POFBG and the second arm terminated. The reflected light was then led back through the fiber coupler and into a CCD-spectrometer (CCS175M, Thorlabs) connected to a PC. The typical reflection spectrum for an unannealed PMMA mPOFBG is shown in Fig. 4. A dynamic gate algorithm [32] was applied on the acquired spectra to achieve a sub-pixel resolution of $\sim 10 \mathrm{pm}$ of the determined Bragg-wavelength. The $\lambda_{B}$ of the resulting mPOFBGs was $\sim 849 \mathrm{~nm}$ in the unannealed fibers and $\sim 847 \mathrm{~nm}$ in the annealed fibers. The difference of $\sim 2$ $\mathrm{nm}$ in $\lambda_{B}$ is due to the annealing induced changes in refractive index from stress relaxation and perhaps birefringence when the PMMA molecular structure gets less ordered.

\section{Etching of $m P O F B G s$}

We believe the changes in POFs during etch are due to combinations of five more or less interrelated, simultaneous, reversible (rev.) and irreversible (irrev.) mechanical and optical effects of varying magnitude, leading to both positive $(+)$ and negative $(-) \lambda_{B}$ shifts. Which effects dominate regarding induced $\lambda_{B}$ shift at a certain time depends on the POF material, processing, solvent used for etching etc. and can be estimated by following the $\lambda_{B}$ shift during the etch. Solvent sorption and etch leads to:

a) Expansion/initial swelling due to added volume of solvent $(+$, rev.).

b) Refractive index change from mixing with solvent having different refractive index than the fiber $(+,-$, rev.).

c) Contraction from stress relaxation/plasticization by polymer molecular rearrangement and etch removal (-, irrev.).

d) Refractive index change from stress relaxation by polymer molecular rearrangement and etch removal of tensile surface stress leading to densification $(+$, irrev.). 


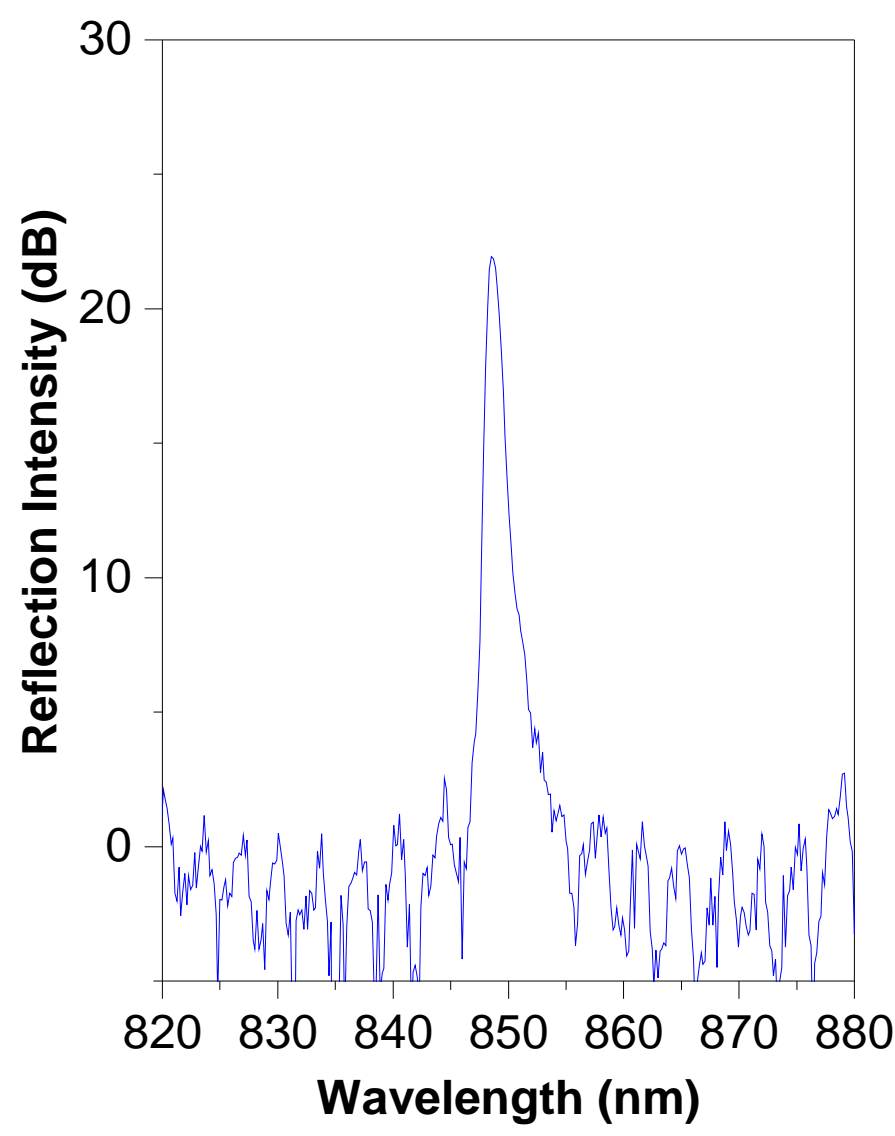

Fig. 4. Reflection spectrum for a typical unannealed $150 \mu \mathrm{m}$ diameter PMMA 2-ring $\mathrm{mPOFBG}$. FWHM is approximately $2 \mathrm{~nm}$.

e) Refractive index change purely from plasticization $(+$, rev.).

Ueberreiter [33] divides the dissolution zone between pure solid polymer and pure solvent in four separate layers: Infiltration, solid swollen, gel and liquid. It is the changes going on during etch in the inward moving infiltration, solid swollen and perhaps to some extent gel layers, which induce changes in $\lambda_{B}$. Swelling starts when the free volume between the polymer chains in the infiltration layer has filled up and initially, when there has been no significant stress relaxation, it is strong enough to expand the fiber along its axis a) and will contribute to a positive shift of $\lambda_{B}$. cf. eqs. (1) and (2). It has even been shown, that polymers (hydrogels) which swell/de-swell in specific chemical environments, can be placed on etched mPOFBGs outside the cladding and in this way induce $\lambda_{B}$ shifts for chemical sensing [34]. However, if the polymer is made too soft, this transducer principle is not working [34], [35]. The $n_{\text {eff }}$ related $\lambda_{B}$ shift due to presence of solvent in the fiber $\mathbf{b}$ ), is, according to the Lorentz-Lorenz equation for binary mixtures, eq. (5), [36], negative if the solvent refractive index is lower than that of the polymer $\left(n_{P M M A}=1.4906\right.$ [37]) and vise versa. In eq. (5), $n_{12}$ is the refractive index of the mixture of component 1 and $2, \alpha=\frac{n_{1}^{2}-1}{n_{1}^{2}+2}, \beta=\frac{n_{2}^{2}-1}{n_{2}^{2}+2}$, $n_{1}$ and $n_{2}$ are the refractive indices of the pure components, $\phi_{i}=\frac{w_{i} \rho_{12}}{\rho_{i}}$ with weight fraction $w_{i}=\frac{m_{i}}{m_{1}+m_{2}}, \rho_{i}$ the density of the pure components, $i=1,2$ and $\rho_{12}$ the mixture density.

$$
n_{12}=\sqrt{\frac{1+2 \phi_{1} \alpha+2 \phi_{2} \beta}{1-\phi_{1} \alpha-\phi_{2} \beta}}
$$

Free energy $\Delta G=\Delta H-T \Delta S$, where $T$ is the absolute temperature, is stored as residual stress in the fiber during the drawing process by increase in latent heat $\Delta H$ and entropy $\Delta S$ decrease due to fiber axis molecular chain alignment ordering [9], [38]. During stress relaxation the stored energy is released again in form of heat and molecular disordering. Outer stressed layers removed by the etch or plasticized by sorption leads to stress redistribution in the remaining fiber. At equilibrium, the axial stress distribution $\sigma_{a x}(r)$, where $r$ is the distance from the fiber center at some cross section with area $A$, is balanced and equation (6) holds [39].

$$
\int_{A} \sigma_{a x}(r) d A=0
$$

So, if the fiber has been drawn as typical for optical fibers [40] and wires [39], such that, at equilibrium, axial residual stress is mainly compressive around the center and tensile closer to the surface, plasticization or etch will result in less tension stress counteracting the compressive and the fiber will shrink, which will cause contraction c) of the FBG and therefore negative shift of $\lambda_{B}$. When the fiber tensile strain $\varepsilon$ is reduced, its volume $V$ decreases with $\Delta V$ according to eq. (7), [41]:

$$
\Delta V=V(1-2 \nu) \varepsilon
$$

where $\nu$ is Poisson's ratio $\left(\nu_{P M M A}=0.4,[42]\right)$. At the same time, this means that the fiber density $\rho$ and hence also the refractive index $n$ increase according to the Lorentz-Lorenz equation for pure substances [43], eq. (8),

$$
n=\sqrt{\frac{M+2 \rho R}{M-\rho R}}
$$

where $M$ is the molecular weight, $R$ the molar refraction and $\rho$ the density. In eq. (2), this FBG $n_{e f f}$ dependency on strain induced volume change is represented by the photoelastic coefficient $P_{\varepsilon}=\frac{\Delta n_{e f f}(\varepsilon)}{n_{e f f}}=\frac{1}{2} n^{2}\left[P_{12}-\nu\left(P_{11}+P_{12}\right)\right]$, where $P_{11}, P_{12}$ are Pockel's coefficients of the strain-optic tensor [4], [44]. In this way d), the shrinkage also contain a $\lambda_{b}$ redshift component by increasing $n_{\text {eff }}$. Here, it should also be mentioned, that the more crystalline a polymer is, the higher are it's density and therefore refractive index, cf. eq. (8). Thus, when the fiber is relaxed, it looses some degree of long range "crystalline" ordering or anisotropy, which might oppositely lead to density and $n_{\text {eff }}$ lowering $\lambda_{B}$ blue-shift. However, we believe this effect is small, because inherently, PMMA is not a semi-crystalline thermoplastic polymer. Plasticization in itself, e), will also affect $n_{\text {eff }}$ in eq. (1). For PMMA, Lamble et al. [45] have demonstrated that the refractive index and the stress-optic coefficient increase linearly for increasing content of the plasticizer dibutyl phthalate (DBP). By using DBP with $\mathrm{n}_{\mathrm{DBP}}=1.4925 \approx \mathrm{n}_{\mathrm{PMMA}}=1.4909$, they ensured that this effect was mainly due to plasticization and not a refractive index binary mixture effect. The maximum amount of DBP was $20 \mathrm{wt} \%$ giving a refractive index change of 0.0048 , which 
in our study would correspond to a $\lambda_{B}$ change of $\sim 3 \mathrm{~nm}$. So, based on this work, we anticipate a $\lambda_{B}$ red-shift component due to plasticization related $n_{\text {eff }}$ increase.

The stronger the solvent interacts with the polymer, the faster are the processes a)-e). For instance, the speed of POF etching is strongly influenced by the initial fiber stress relaxation level, see Fig. 5. Unannealed POFs etch much faster

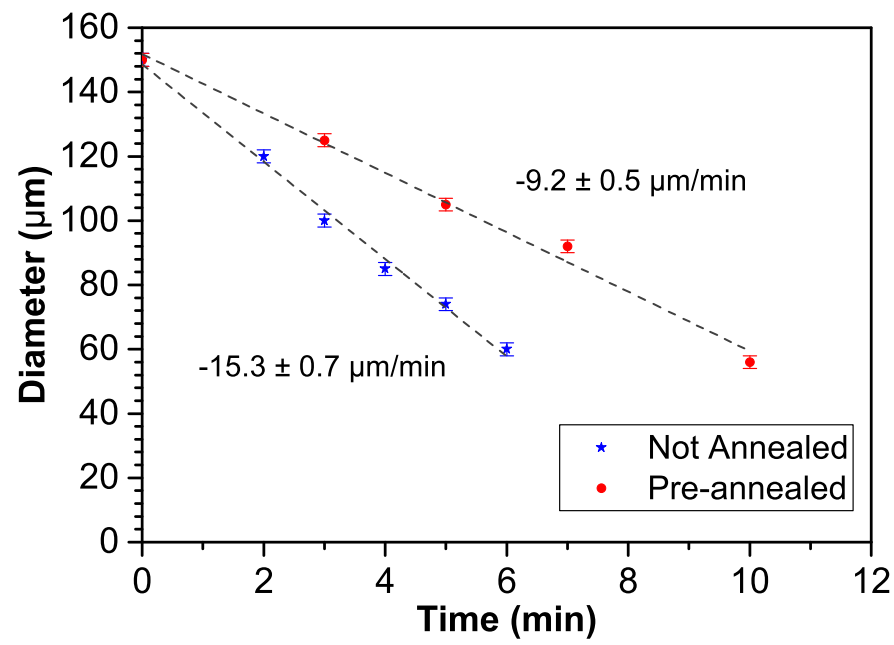

Fig. 5. Diameter etching rate in pure acetone of unannealed and pre-annealed PMMA mPOFs with initial diameters of approximately $150 \mu \mathrm{m}$.

than annealed because residual stress lowers the free energy barrier for dissolution. In terms of HSP thermodynamics, for unannealed, unrelaxed POFs, $R_{0}$ is larger and therefore $R E D$ lower for the same solvent. When the polymer solubility is increased by better solvent HSP match, so are swelling, dissolution and solvent diffusivity in the polymer [20], and consequently etch speed. Detailed modeling of polymer dissolution kinetics has been described by e.g. Miller Chou et al. [46] and Narasimhan et al. [47], [48]. For small molecules diffusion is often much faster than polymer chain stress relaxation movement. This is seen from the study presented in Fig. 6. When an unannealed POFBG is immersed in water, expansion

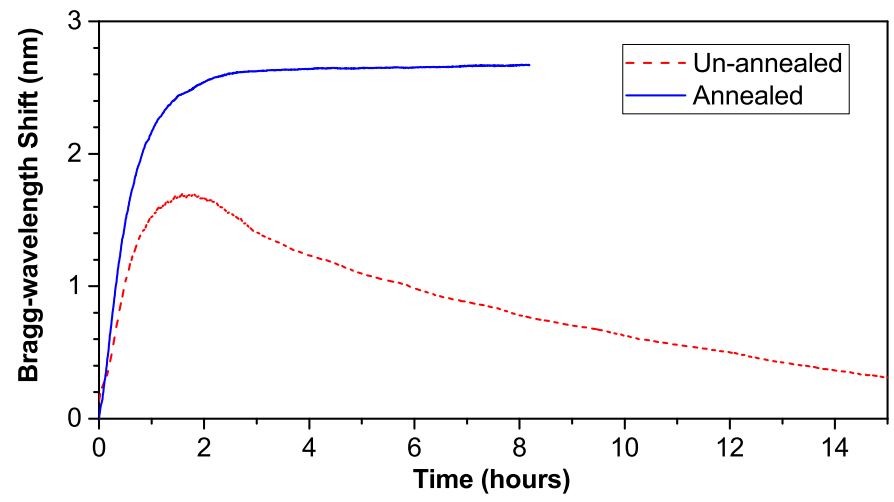

Fig. 6. Bragg-wavelength response of two $150 \mu \mathrm{m}$ diameter PMMA mPOFs after being immersed in distilled water at room temperature. The annealed mPOFBG absorbs water and saturates with a total shift of $\sim 2.7 \mathrm{~nm}$. The unannealed mPOFBG starts annealing at room temperature as water is absorbed.

a) of the fiber and therefore red-shift of $\lambda_{B}$ due to fast water diffusion initially dominates over $\lambda_{B}$ blue-shift due to any total refractive index lowering b), d), e), $\mathrm{n}_{\text {water }}=1.3324$ and residual axial stress relaxation shrinkage c), i.e. fiber length reduction. The three contributions to refractive index change are small at the PMMA water saturation $(\sim 1.5 \mathrm{wt} \%)$ and of opposite sign and together do probably not contribute much to the total $\lambda_{B}$ shift. When the fiber has become saturated with water, it is sufficiently soft for $\lambda_{B}$ stress relaxation blue-shift c) to become dominating. For the annealed fiber there is no residual stress in the fiber and when it is immersed in water only $\lambda_{B}$ red-shift a) is observed. Again, some minor negative b) and positive d), e) contributions to the shift are expected to come from the refractive index changes. For unannealed PMMA based POFs we have earlier seen a similar behavior on a much longer time scale in methanol/water 50/50 v/v\% [19]. The concentration of small water molecules in this mixture is high enough to, initially, induce a fiber length increase a) dominating over any total refractive index lowering b), d), e) and residual axial stress relaxation shrinkage c), i.e. we observe a $\lambda_{B}$ red-shift. After some time this change to dominating POF length reduction c), and thus $\lambda_{B}$ blue-shift due to swelling induced stress relaxation. However, in this case with methanol $\left(\mathrm{n}_{\text {methanol }}=1.3145\right.$, [37]) swelling, the saturation level is much higher and the refractive index negative contribution b) to the shift might be larger. When the $R E D$ number is lowered by increasing the methanol concentration to $60 \mathrm{v} / \mathrm{v} \%$ or $70 \mathrm{v} / \mathrm{v} \%, \lambda_{B}$ blue-shift b), c) dominates at all times over the total red-shift a), d), e) probably mainly due to increased swelling induced stress relaxation speed c). Likewise, stress relaxation c) $\lambda_{B}$ blue-shift dominates at all times during annealing of the fibers in this study at $65^{\circ} \mathrm{C}$ in water, see Fig. 7. The observed annealing blue-shift is $81 \mathrm{~nm}$, which is similar to the shifts observed by Fasano et al. [19] for the methanol/water solvent relaxation mixtures. The initial dominance over red-shift contributions a), d), e) is mainly due to much faster temperature than water equilibrium. Later, like for the methanol/water mixtures with high methanol content, the elevated temperature also contributes to the dominance through lowering of the PMMA-water $R E D$ number, which leads to higher water saturation concentration b), c).

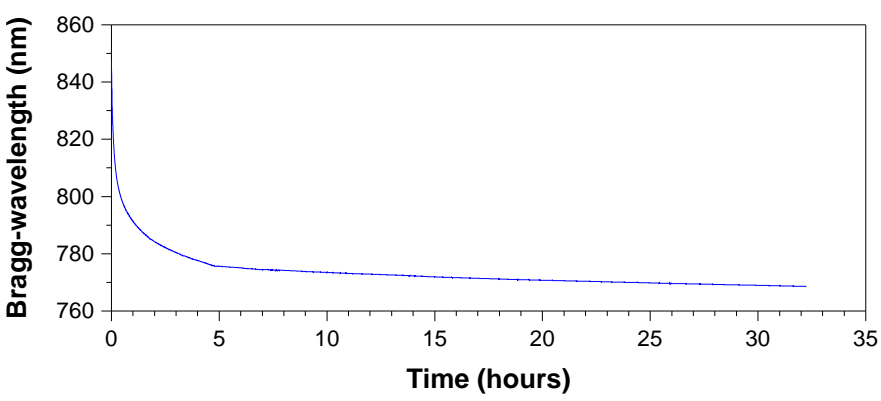

Fig. 7. Bragg-wavelength response for a $150 \mu \mathrm{m}$ diameter 2-ring $\mathrm{mPOFBG}$ during annealing in water at $65^{\circ} \mathrm{C}$. After 32 hours, the Bragg-wavelength had shifted from $849 \mathrm{~nm}$ to $768 \mathrm{~nm}$ (a shift of $81 \mathrm{~nm}$ ).

In this work, to study the influence of etching on the mechanical and thermal mPOFBG properties, the end tips of the mPOFs were sealed using a UV curable adhesive (NOA78, Norland Products, Inc.) to avoid acetone from entering the 
air channels of the fiber. The mPOFBGs were etched in pure acetone (99.9\%, Sigma Aldrich). In works done by others [10]-[14], [22]-[24], mixtures of acetone and methanol have been used due to improved surface quality, but as explained, in our case the best surface quality was obtained using acetone only. The etching process was done while monitoring the Bragg-wavelength by immersing $\sim 8 \mathrm{~cm}$ of the fiber (including the FBG) in a test tube filled with acetone placed in a water bath at $23.4^{\circ} \mathrm{C}$ for thermal stabilization. Fig. 8 shows the behavior of three mPOFs annealed before FBG inscription and etched from $150 \mu \mathrm{m}$ diameter to $125 \mu \mathrm{m}, 92 \mu \mathrm{m}$ and $56 \mu \mathrm{m}$. Note the much smaller time scale and $\lambda_{B}$ shifts when etching,

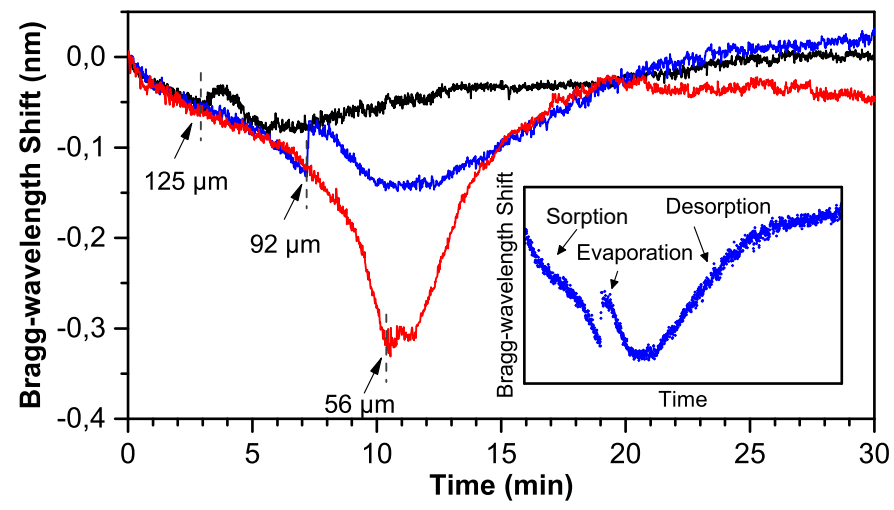

Fig. 8. Response of FBGs inscribed in pre-annealed mPOFs during etching in pure acetone. Vertical dashed lines represent the time, at which each sensor was removed from the solvent and left to stabilize under room conditions. Inset: Zoom of the response during etching of the $92 \mu \mathrm{m}$ diameter mPOFBG, which was etched for 7 mins., showing the different phases during and after etching.

compared to the earlier presented work. Since the POF is stress free, the initial negative $\lambda_{B}$ shift cannot be attributed to stress relaxation $\mathbf{c}), \mathbf{d})$, which is irreversible, but only negative change in effective refractive index due to high concentrations of acetone b) $\left(\mathrm{n}_{\mathrm{PMMA}}=1.4906, \mathrm{n}_{\text {Acetone }}=1.3544\right.$ [37]). This effect largely dominates over any $\lambda_{B}$ red-shift due to sorption induced POF expansion a) and plasticization refractive index increase e). Importantly, the shift is very reversible, i.e. most of the shifts have disappeared after a desorption period. However, for the fiber etched to $56 \mu \mathrm{m}$ there is still a small blueshift after 20 mins. desorption, which indicates that there is still some acetone left in the material. Evidently, also at this time, the negative effect of $\mathbf{b}$ ) is larger than the positive of a) and e). The fast and small $\lambda_{B}$ red-shifts observed when taking the POFBGs out of solution are due to cooling when the liquid acetone at the surface evaporates. After cooling, the negative shift continues for as long as there is solvent at high concentration near the fiber surface, which can diffuse to lower concentrations closer to the sensing FBG in the fiber core. Fig. 9 shows the behavior of three POFs unannealed before FBG inscription and etched from $150 \mu \mathrm{m}$ diameter to $120 \mu \mathrm{m}, 100 \mu \mathrm{m}$ and $74 \mu \mathrm{m}$. Note again the faster etch due to lower $R E D$ number induced by residual stress. During etch, these POFs behave much like the described similar fibers dipped in water, cf. Fig. 6, and methanol/water $50 / 50 \mathrm{v} / \mathrm{v} \%$ [19]. Initially, for all three fibers, $\lambda_{B}$ red-shift effects a), d), e) dominates over b), c), due to faster diffusion than

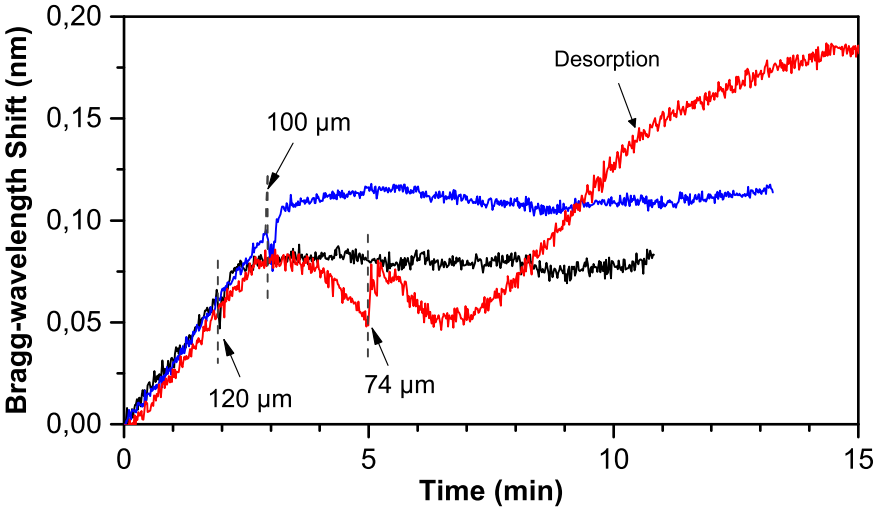

Fig. 9. Response of FBGs inscribed in unannealed mPOFs during etching in pure acetone. Vertical dashed lines represent the time at which, each sensor was removed from the solvent and left to stabilize under room conditions.

stress relaxing polymer chain rearrangement. Only the most etched ( $74 \mu \mathrm{m}$ diameter) POF is etched sufficiently long time (5 mins.) for the fiber relaxation shrinkage c) together with the effective refractive index negative change b) to become dominating and be observed as a $\lambda_{B}$ blue-shift. Like for the annealed mPOFBGs, after the etch has ended, there is still sufficiently much acetone in the fiber near the surface for relaxation related blue-shift, to continue for $\sim 1.5$ mins., where-after the concentration gets too low and the fiber length increase related $\lambda_{B}$ red-shift a) again begins to dominate. The POFBG etched to $100 \mu \mathrm{m}$ diameter is taken out of the acetone after $\sim 3$ mins., which is close to the time where relaxation $\lambda_{B}$ blue shift begins to dominate and therefore the magnitude and duration of this shift is not as pronounced. The subsequent $\lambda_{B}$ red-shift stops much earlier ( 2 mins.) because of less negative near surface to center acetone concentration gradient in the fiber. The POFBG etched to $120 \mu \mathrm{m}$ diameter is taken out of the acetone after $\sim 2$ mins. At this time the $\lambda_{B}$ red-shift is still so dominating that only the continued $\lambda_{B}$ red-shift is observed for the shortest time ( 1 min.) due to smallest negative acetone concentration gradient in the fiber. Note the overall small changes, indicating that these counteracting effects are almost of equal magnitude. Since probably none of the fibers get fully relaxed during the etch, the $R E D$ number is still lower than for the annealed POF, which means that the acetone likes even more to stay at relatively high concentration inside the PMMA. After etch, this leads to constant $\lambda_{B}$ red-shift due to expansion a) and plasticization e) dominating over refractive index $\lambda_{B}$ blue-shift b), which was the dominating effect for the annealed POFBGs.

\section{E. Thermal response of etched $m P O F B G s$}

Due to the hygroscopic nature of PMMA, the thermal response of the pre-annealed mPOFBGs was measured with the FBG immersed in water. A test tube filled with demineralized water was placed in a water bath on a feedback controlled heating plate while stirring. A thermometer was placed in the test tube to monitor the temperature. The temperature was stabilized at $24.5^{\circ} \mathrm{C} \pm 0.1{ }^{\circ} \mathrm{C}$ and the mPOFBG was left in the test tube overnight to completely saturate the FBG with 
water, causing a positive shift in the Bragg-wavelength of $\sim 2.7$ $\mathrm{nm}$, see Fig. 6. In this way, it is ensured that the measured thermal response of the FBG is not influenced by changes in the relative humidity but only small changes in PMMA saturation level as the temperature is changed. The thermal response was only measured on the pre-annealed fibers below the annealing temperature of $65^{\circ} \mathrm{C}$ to avoid any influence from thermally induced relaxation of the mPOFBGs.

The thermal responses of an un-etched and etched (diameters: $150 \mu \mathrm{m}, 102 \mu \mathrm{m}$ and $56 \mu \mathrm{m})$ mPOFBGs are shown in Fig. 10 and Fig. 11, where the zero-point of the Braggwavelength shift has been chosen, such that $\Delta \lambda_{B}=0$ at $24.5^{\circ} \mathrm{C}$ for all the FBGs. As seen in Fig. 10, showing the

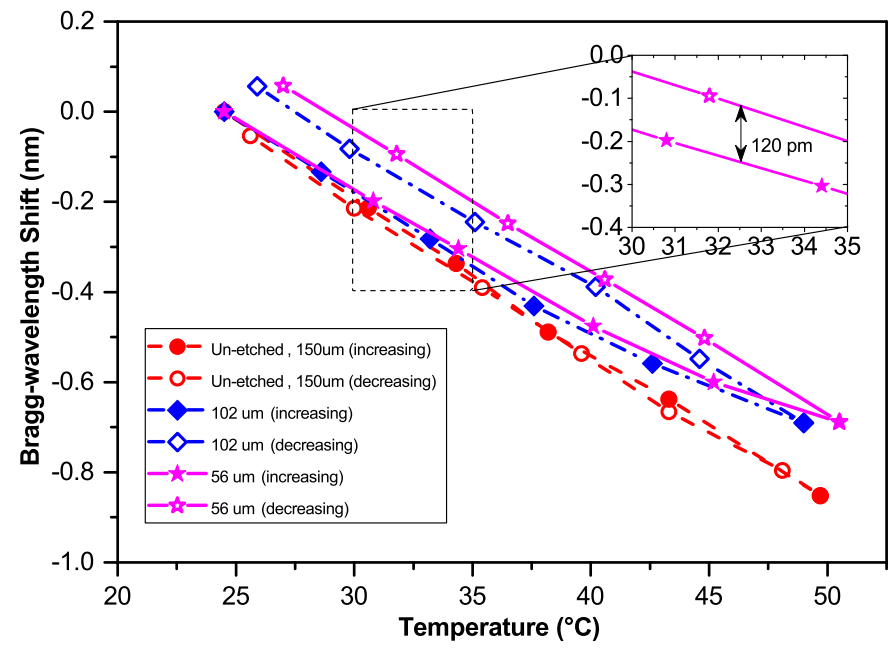

Fig. 10. First thermal cycle. The unetched fiber exhibits linear behavior with minimal hysteresis. The etched fibers exhibit a nonlinear response under heating, but linear when cooled. This behavior is due to heat induced solvent desorption.

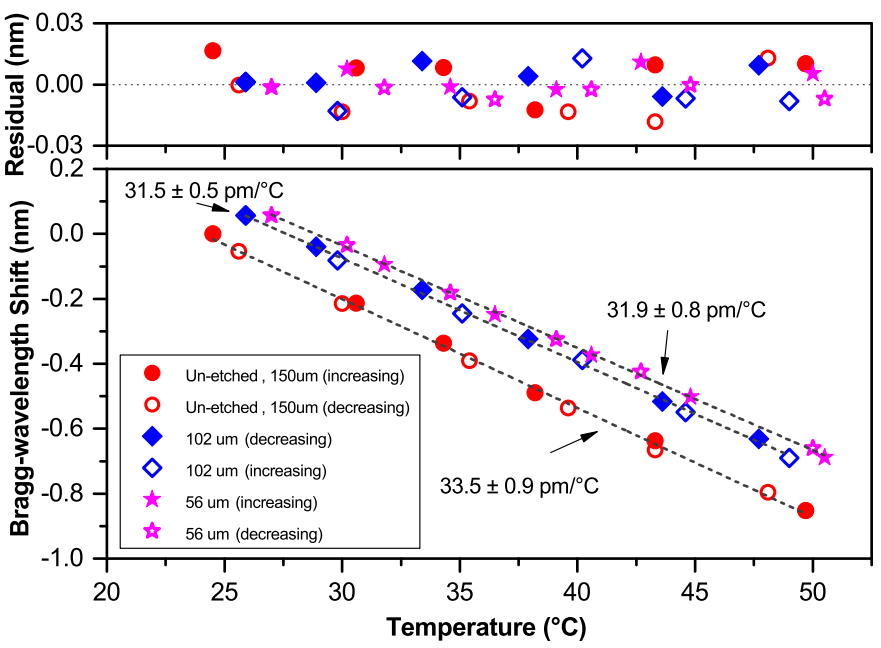

Fig. 11. Second thermal cycle of the etched mPOFBGs compared with first cycle of the unetched mPOFBG. Dashed lines represent the linear fitting of data. Top: Deviation of each data point from the linear fit.

initial cycle of thermal variation, the un-etched FBG has a highly linear response with a sensitivity of $-33.5 \mathrm{pm} /{ }^{\circ} \mathrm{C} \pm$ $0.9 \mathrm{pm} /{ }^{\circ} \mathrm{C}$ with a similar path for increasing and decreasing temperature. The etched mPOFBGs, on the other hand, exhibit a nonlinear response as the temperature is increased but linear response as temperature is decreased. This behavior is associated with desorption of the residual acetone originating from the etching process as the fiber is heated, causing a positive shift of the Bragg-wavelength, i.e. the reverse of $\mathbf{b}$ ) in the previous section. In other words, acetone with a lower refractive index than that of the fiber is driven out, which leads to increase of $n_{e f f}$. Note also, that the gain in $\lambda_{B}$ correspond well with that lost at the end of etch, Fig. 8. As the mPOFBG is subsequently cooled, no further desorption is happening, and the thermal response becomes linear as in the un-etched case. In Fig. 11, the thermal response of the etched mPOFBGs related to the second cycle of temperature variation is shown and compared with the un-etched $\mathrm{mPOFBG}$, showing very similar responses with sensitivities of $-31.9 \mathrm{pm} /{ }^{\circ} \mathrm{C} \pm 0.8$ $\mathrm{pm} /{ }^{\circ} \mathrm{C}(56 \mu \mathrm{m})$ and $-31.5 \mathrm{pm} /{ }^{\circ} \mathrm{C} \pm 0.5 \mathrm{pm} /{ }^{\circ} \mathrm{C}(102 \mu \mathrm{m})$. This demonstrates, that reducing the diameter of the fiber by solvent etching, does not have a significant impact on the thermal response of the mPOFBG. This result is in contrast to the results presented by Bhowmik et al. [11], [12], [14], who found linear diameter correlated thermal responses with significantly increased sensitivity of etched step-index PMMA FBGs. The cause of this discrepancy may be that the thermal variation in these references was done without humidity control. As the temperature is increased the relative humidity decreases, which means that the surrounding air can hold more water. This induces fiber desorption of water and an additional blueshift of the Bragg-wavelength, which could dominate the redshift caused by solvent desorption. The humidity induced shift becomes even more apparent as the fiber diameter is reduced due to a rapidly lowered response time [10]. A nonlinear, diameter-independent thermal response of etched step-index PMMA-POFBGs was also observed by $\mathrm{Hu}$ et al. [24] at a constant relative humidity of $50 \%$, however the grating response for decreasing temperature was not shown, and no further elaboration on the observed behavior was made. Furthermore, it is not mentioned in these papers whether their fibers were pre-annealed and up-down cycles are missing.

\section{F. Mechanical sensing characteristics of etched mPOFBGs}

The strain sensitivity and force-sensitivity of both the etched and unetched mPOFBGs were measured using the setup shown in Fig. 12. The mPOFBG was mounted in clamps between a

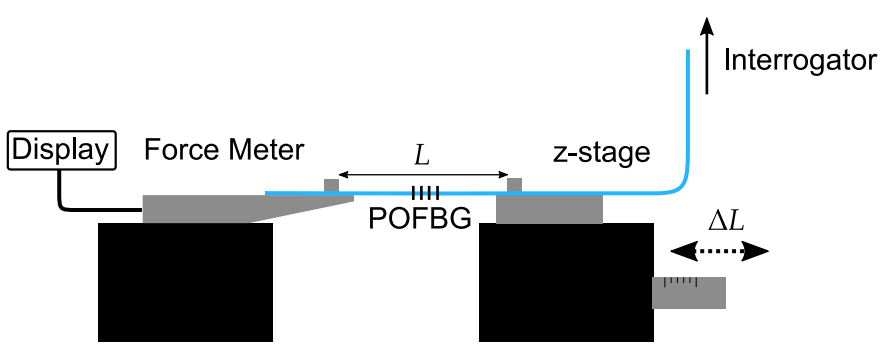

Fig. 12. Setup used to measure the force and strain sensitivities of etched and unetched mPOFBGs.

fixed force meter (Thorlabs FSC102, $1 \mathrm{mN}$ resolution) and 
a translation stage with a resolution of $10 \mu \mathrm{m}$ with the FBG section in between. The initial length $L$ between the clamps was measured to be $46.2 \mathrm{~mm} \pm 0.1 \mathrm{~mm}$. By translating the stage by an amount $\Delta L$, the applied change in strain $\Delta \varepsilon=\frac{\Delta L}{L}$ could be calculated. At each level of strain, the mPOFBG was allowed to stabilize for 3 mins. after which $\lambda_{B}$ was sampled and the corresponding force acquired from the force meter. For all fibers tested, $\Delta L$ was varied between zero and $0.25 \mathrm{~mm}$ in steps of $0.05 \mathrm{~mm}$, corresponding to a maximum change in strain of $\Delta \varepsilon=0.54 \%$. After reaching maximum strain, the fiber was relaxed for approximately 5 minutes before repeating the cycle. For each sensor, the cycle was repeated three times. Only data for increasing strain was recorded due to an observed backlash/hysteresis in the force sensor, which would affect the response of the mPOFBGs. Observing the deload of POFs is relevant due to the viscoelastic behavior of polymers, which leads to hysteresis, which has been shown to be both strain and time dependent [49]. After being completely released from maximum strain, $\lambda_{B}$ drops fast (elastic behavior) but then starts a slow recovery (viscous behavior). Due to the limited strain range used in this investigation, the viscoelastic effect is limited and is fully recovered within 5 mins.

The strain sensitivity was determined as the slope of the acquired $\left(\Delta \varepsilon, \Delta \lambda_{B}\right)$ data for each sensor. Young's modulus $E$ was calculated from eq. (9),

$$
E=\frac{4 k L}{\pi D^{2}}
$$

where $k$ is the spring constant in Hooke's law, $\Delta F=k \Delta L, L$ is the distance between the fixing points holding the mPOFBG and $D$ is the fiber diameter. Thus, by evaluating $k$ from the experiments described above, Young's modulus of the mPOFs could be determined. The results are shown in Fig. 13 and Fig. 14 and demonstrates that both the strain sensitivity and Young's modulus are affected by the etching process, the most significant changes being observed for the unannealed mPOFBGs. The obtained strain sensitivities are shown in Fig. 13 and are seen to increase, as the diameter of the fiber decreases due to solvent etching. The magnitude of change,

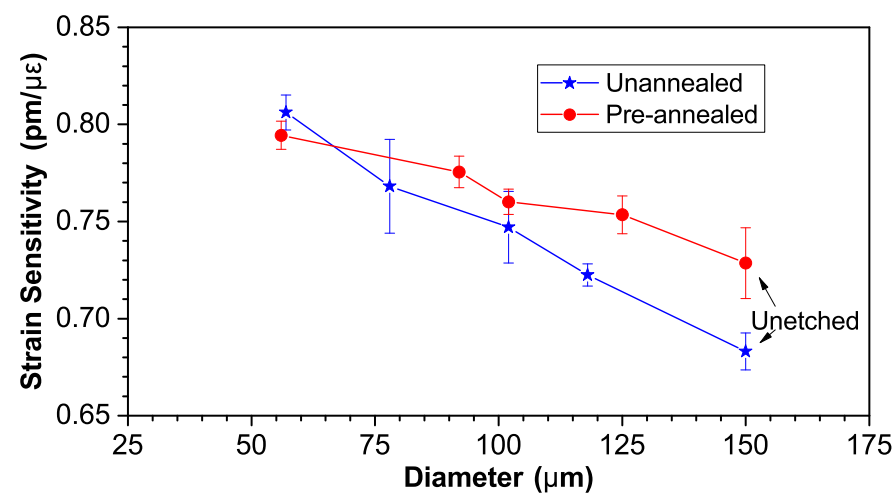

Fig. 13. Measured strain sensitivity for mPOFBGs etched in acetone. The error bars denote the standard error of the slope obtained by linear fitting multiplied by a coverage factor of 2.11 taken as the inverse T-distribution at a $95 \%$ confidence level with 17 degrees of freedom, which gives a measure of the repeatability of the measurements. however, is quite modest. For the unannealed mPOFBGs a change from $0.68 \mathrm{pm} / \mu \varepsilon \pm 0.01 \mathrm{pm} / \mu \varepsilon(150 \mu \mathrm{m}$ diameter $)$ to $0.80 \mathrm{pm} / \mu \varepsilon \pm 0.01 \mathrm{pm} / \mu \varepsilon$ (57 $\mu \mathrm{m}$ diameter) corresponding to $18 \%$, is observed. For the pre-annealed mPOFBGs, it changes from $0.73 \mathrm{pm} / \mu \varepsilon \pm 0.02 \mathrm{pm} / \mu \varepsilon(150 \mu \mathrm{m}$ diameter $)$ to 0.79 $\mathrm{pm} / \mu \varepsilon \pm 0.01 \mathrm{pm} / \mu \varepsilon$ (56 $\mu \mathrm{m}$ diameter) corresponding to a $8 \%$ change. It is also observed, that there is a significant difference in $E$ between the unannealed and annealed mPOFBGs, see Fig. 14. The modulus of the unannealed mPOFBG

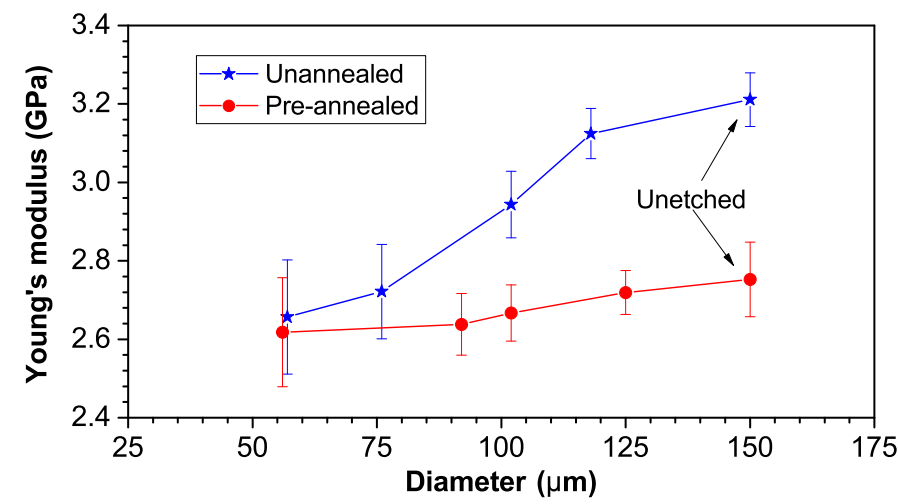

Fig. 14. Measured Young's modulus $E$ of etched mPOFs.

was measured to be $3.21 \mathrm{GPa} \pm 0.07 \mathrm{GPa}$ whereas it for the annealed $\mathrm{mPOFBG}$ was $2.75 \mathrm{GPa} \pm 0.10 \mathrm{GPa}$. This is expected, as the polymer chains in unannealed fibers have a larger degree of orientation along the fiber axis [9], [38] and thus carry a greater part of the load on the stronger covalent bonds [50]. The Young's modulus of the unannealed fiber is seen to decrease during the etching process. The modulus for the fiber etched to $57 \mu \mathrm{m}$ was measured to be $2.66 \mathrm{GPa} \pm 0.15$ $\mathrm{GPa}$, which is a $17 \%$ decrease compared to the modulus of the unetched fiber. Only a small decrease in the measured Young's modulus of the annealed fibers due to solvent etching is observed, and the measurement uncertainties makes it difficult to make a conclusion in this case. However, since this decrease is also observed by Leal-Junior et al. [15], we are confident it is due to plasticization. The large decrease in $E$ for the unannealed mPOFBG during etch can be accounted for with three components:

1) Stress relaxation c) by polymer molecular rearrangement in the FBG. As discussed earlier, this was not observed to become dominating regarding $\lambda_{B}$ blue-shift during the short etching process, but this does not mean it was not significant.

2) Tensile stress near the surface will also lead to more orientation along the fiber here and thus high contribution to the total $E$ [50]. This will be etched away during etch and could explain some of the the $E$ lowering.

3) Plasticization. Note, that the unannealed $\mathrm{mPOFBG}$ when etched reach the same low $E$ level as the annealed in Fig. 14.

In order to further investigate this, an unannealed mPOFBG was prepared and it's Young's modulus $E$ measured. Subsequently, while monitoring $\lambda_{B}$, it was submerged into distilled water at $65^{\circ} \mathrm{C}$, which starts the annealing of residual stress, 
causing $\lambda_{B}$ blue-shift. After observing small wavelength shifts the fiber was removed from the water and allowed to stabilize in room conditions for one hour after which $E$ was measured again. This process was repeated four times, each time increasing the annealing duration up to a total annealing time of approximately 30 minutes. The results are shown in Fig. 15, where the strain sensitivity is given as the fractional value $\frac{S_{\varepsilon}}{\lambda_{B}}$, due to the general scaling of the sensitivity with wavelength, see eq. (2). It is seen, that Young's modulus is decreasing

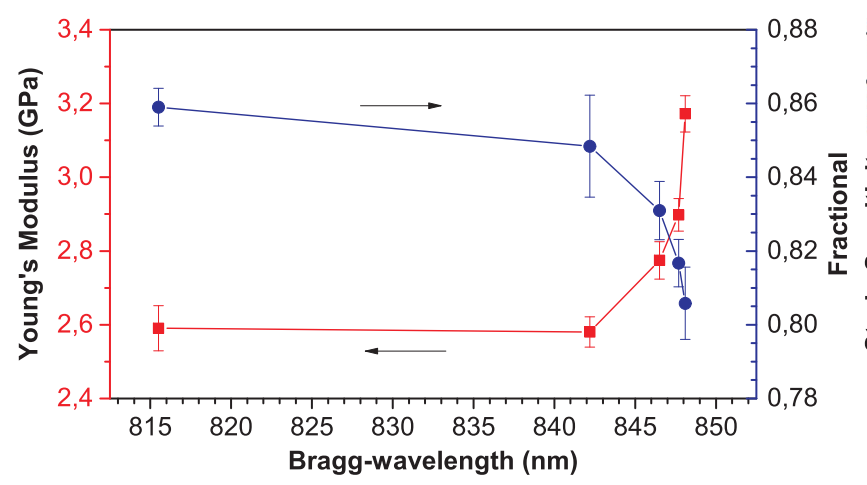

Fig. 15. Measured Young's modulus (red) and fractional strain sensitivity (blue) for an initially unannealed $150 \mu \mathrm{m}$ mPOFBG for different degrees of annealing, which is represented by a blue-shift of the Bragg-wavelength.

and strain sensitivity is increasing as the fiber is annealed due to stress relaxation c), however, it is also seen that the $\lambda_{B}$ shift "required" (and thus the degree of annealing) for Young's modulus and strain sensitivity to become close to that of the etched unannealed mPOFBG $(57 \mu \mathrm{m}$ diameter $)$ in Fig. 13 and Fig. 14 is approximately $9 \mathrm{~nm}$. Since this large shift is more than compensated during etch, see Fig. 9, the expansion a) of the mPOFBG must be very large. Further, since approximately the same level of $E$ is reached by etching to a diameter of 57 $\mu \mathrm{m}$ as in this annealing, the etched fibers must be almost fully $E$ relaxed long before full stress relaxation, which requires a blue-shift of at least $81 \mathrm{~nm}$ as shown in Fig. 7 and by Fasano et al. [19]. Since etching and annealing relax the surface first, this may indicate, that the high $E$ of unannealed fibers originates from and is strongly dependent on the presence of molecules within a distance of $\sim 47 \mu \mathrm{m}$ to the surface, oriented with length direction frozen-in highly parallel to the fiber axis during drawing, cf. the $E$ influence component 2) above.

The force sensitivity of the mPOFBGs were found as the slope of $\left(\Delta F, \Delta \lambda_{B}\right)$ data, see Fig. 16, showing the force calibration curves of three pre-annealed mPOFBGs. The results of both unannealed and pre-annealed mPOFBGs are shown in Fig. 17 and compared to the calculated values using eq. (2) and fixed values for $E$ and $S_{\varepsilon}(2.6 \mathrm{GPa}$ and $0.75 \mathrm{pm} / \mu \varepsilon$, respectively). From this figure, it can be seen that the force sensitivity increases greatly with reduced diameter as expected and that the relatively small changes in strain sensitivity and Young's modulus introduced by the etching process do not have a big effect. The dominating effect is the reduced cross sectional area of the fiber. These findings are also in good agreement with similar studies [15], [16].

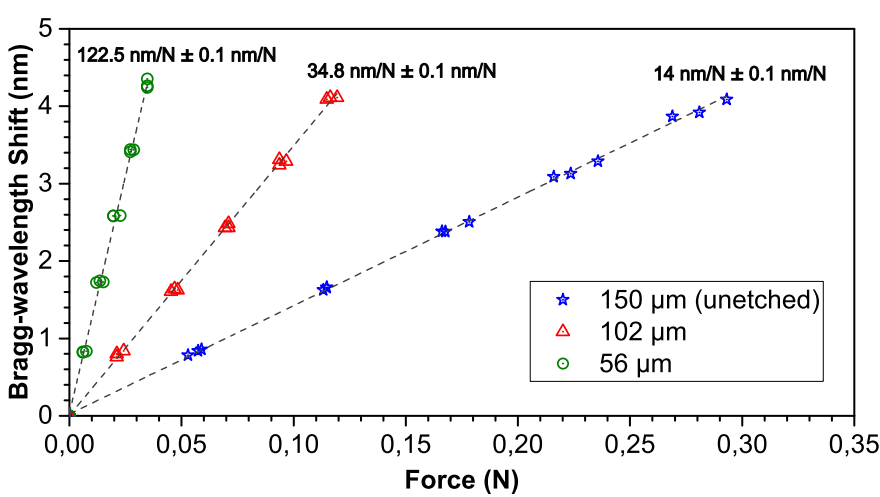

Fig. 16. Response of mPOFBGs (pre-annealed) towards tensile force.

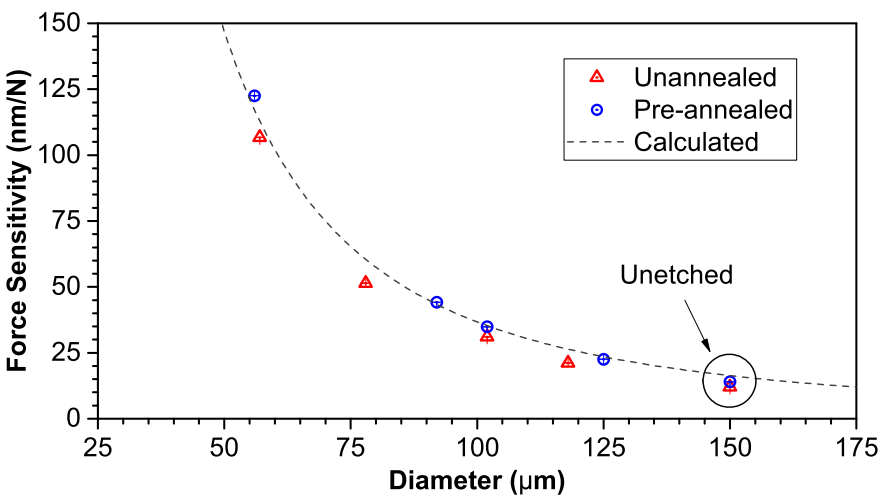

Fig. 17. Force sensitivity $S_{F}$ of etched mPOFBGs compared with calculated value $S_{F}=\frac{S_{\varepsilon}}{E A}$, see eq. (2) - using $S_{\varepsilon}=0.75 \mathrm{pm} / \mu \varepsilon$ and $E=2.6 \mathrm{GPa}$.

\section{CONCLUSION}

For our PMMA based mPOFBGs etched in acetone we can conclude:

- We have found theoretical, thermal and mechanical evidence for trapped, residual solvent in the polymer matrix after etch: According to HSP theory, solvents good for etching tend to stay inside the polymer. For annealed mPOFBGs, thermal response is only nonlinear during a first temperature rise where the solvent, which act as a plasticizer, is driven out. Due to etch we have found that Young's modulus is reduced for both unannealed and annealed mPOFBGs to a level below that of the annealed before etch, which indicates plasticization.

- Removal of the acetone plasticizing residuals by the thermal treatment results in a stable linear response with a thermal sensitivity indistinguishable of that of the unetched POFBG.

- Our unannealed mPOFBGs get fully Young's modulus $E$ relaxed by polymer molecular rearrangement and removal when using acetone etchant. They do probably not get fully stress relaxed.

- The high Young's modulus $E$ of unannealed fibers is a surface (first $\sim 47 \mu \mathrm{m}$ ) effect. It seems to originate from and be strongly dependent on the presence of molecule chains near the surface with length direction oriented highly parallel to the fiber axis. 
- Good solvents for POF etching are characterized by $R E D \lesssim 1$ and relatively high $M V o l$.

- Due to the differences in residual stresses, unannealed and annealed mPOFBGs etch very differently. We have demonstrated that these differences are well explained in terms of HSP theory.

- The mPOFBG force sensitivity increases greatly with reduced diameter and the relatively small changes in strain sensitivity and Young's modulus introduced by the etching process in this case do not have a big effect. The dominating effect in this acetone PMMA mPOFBG etch, is the reduced cross sectional area of the fiber.

\section{ACKNOWLEDGMENT}

This work was supported by: The Danish Innovation Foundation as part of the innovation consortium BIOFORS (contract no. 1382-00058B); The European Maritime and Fisheries Fund; The Danish Fisheries Agency and The People Programme (Marie Curie Actions) of the European Union's Seventh Framework Programme FP7/2007-2013/ under REA Grant Agreement 608382.

\section{REFERENCES}

[1] D. J. Webb, "Fibre bragg grating sensors in polymer optical fibres," Measurement Science and Technology, vol. 26, no. 9, p. 092004, 2015.

[2] H. Dobb, D. Webb, K. Kalli, A. Argyros, M. Large, and M. van Eijkelenborg, "Continuous wave ultraviolet light-induced fiber bragg gratings in few- and single-mode microstructured polymer optical fibers," Optics Letters, vol. 30, no. 24, pp. 3296-3298, 2005.

[3] Z. Xiong, G. Peng, B. Wu, and P. Chu, "Highly tunable bragg gratings in single-mode polymer optical fibers," Ieee Photonics Technology Letters, vol. 11, no. 3, pp. 352-354, 1999.

[4] R. Kashyap, Fiber Bragg Gratings, 2nd ed. Elsevier Inc., 2010.

[5] J. K. M. Pedersen, J. Janting, G. Woyessa, K. Nielsen, and O. Bang, "All-Polymer fiber Bragg grating based $\mathrm{pH}$ sensor," in 26th International Conference on Optical Fiber Sensors. Optical Society of America, 2018, p. ThE52. [Online]. Available: http://www.osapublishing.org/abstract.cfm?URI=OFS-2018-ThE52

[6] X. Liu, X. Zhang, J. Cong, J. Xu, and K. Chen, "Demonstration of etched cladding fiber Bragg grating-based sensors with hydrogel coating," Sensors and Actuators, B: Chemical, vol. 96, no. 1-2, pp. 468472, 2003

[7] S. Sridevi, K. S. Vasu, S. Asokan, and A. K. Sood, "Sensitive detection of C-reactive protein using optical fiber Bragg gratings," Biosensors and Bioelectronics, vol. 65, pp. 251-256, 2015.

[8] V. N. K. Pabbisetti and S. S. Madhuvarasu, "Hydrogelcoated fiber Bragg grating sensor for $\mathrm{pH}$ monitoring," Optical Engineering, vol. 55, no. 6, p. 066112, 2016. [Online]. Available: http://opticalengineering.spiedigitallibrary.org/article.aspx?doi=10.1117/ 1.OE.55.6.066112

[9] H. Hassan, O. Bang, and J. Janting, "Polymer optical fiber tip mass production etch mechanism to achieve CPC shape for improved biosensor performance," Sensors, vol. 19, no. 2, p. 285, Jan 2019. [Online]. Available: http://dx.doi.org/10.3390/s19020285

[10] G. Rajan, Y. M. Noor, B. Liu, E. Ambikairaja, D. J. Webb, and G. D. Peng, "A fast response intrinsic humidity sensor based on an etched singlemode polymer fiber Bragg grating," Sensors and Actuators, A: Physical, vol. 203, pp. 107-111, 2013. [Online]. Available: http://dx.doi.org/10.1016/j.sna.2013.08.036

[11] K. Bhowmik, G.-D. Peng, Y. Luo, E. Ambikairajah, V. Lovric, W. R. Walsh, and G. Rajan, "Experimental Study and Analysis of Hydrostatic Pressure Sensitivity of Polymer Fibre Bragg Gratings," Journal of Lightwave Technology, vol. 33, no. 12, pp. 2456-2462, 2015. [Online]. Available: http://ieeexplore.ieee.org/document/6998928/

[12] _ "Etching Process Related Changes and Effects on Solid-Core Single-Mode Polymer Optical Fiber Grating," IEEE Photonics Journal, vol. 8, no. 1, pp. 1-9, 2016. [Online]. Available: http://ieeexplore.ieee.org/lpdocs/epic03/wrapper.htm?arnumber=7397839
[13] K. Bhowmik, G. D. Peng, Y. Luo, E. Ambikairajah, V. Lovric, W. R. Walsh, and G. Rajan, "High intrinsic sensitivity etched polymer fiber Bragg grating pair for simultaneous strain and temperature measurements," IEEE Sensors Journal, vol. 16, no. 8, pp. 2453-2459, 2016.

[14] K. Bhowmik, G. D. Peng, E. Ambikairajah, V. Lovric, W. R. Walsh, B. G. Prusty, and G. Rajan, "Intrinsic high-sensitivity sensors based on etched single-mode polymer optical fibers," IEEE Photonics Technology Letters, vol. 27, no. 6, pp. 604-607, 2015.

[15] A. Leal-Junior, A. Frizera, C. Marques, and M. J. Pontes, "Mechanical properties characterization of polymethyl methacrylate polymer optical fibers after thermal and chemical treatments," Optical Fiber Technology, vol. 43, pp. 106-111, 2018.

[16] A. Pospori, C. Marques, D. Sáez-Rodríguez, K. Nielsen, O. Bang, and D. Webb, "Thermal and chemical treatment of polymer optical fiber bragg grating sensors for enhanced mechanical sensitivity," Optical Fiber Technology, vol. 36, pp. 68 - 74, 2017. [Online]. Available: http://www.sciencedirect.com/science/article/pii/S106852001730007X

[17] W. Yuan, A. Stefani, M. Bache, T. Jacobsen, B. Rose, N. HerholdtRasmussen, F. K. Nielsen, S. Andresen, O. B. Sørensen, K. S. Hansen, and O. Bang, "Improved thermal and strain performance of annealed polymer optical fiber Bragg gratings," Optics Communications, vol. 284, no. 1, pp. 176-182, 2011. [Online]. Available: http://dx.doi.org/10.1016/j.optcom.2010.08.069

[18] G. Woyessa, K. Nielsen, A. Stefani, C. Markos, and O. Bang, "Temperature insensitive hysteresis free highly sensitive polymer optical fiber Bragg grating humidity sensor." Optics express, vol. 24, no. 2, pp. 1206-13, 2016. [Online]. Available: http://www.osapublishing.org/viewmedia.cfm?uri=oe-24-2$1206 \&$ seq $=0 \& \mathrm{html}=$ true

[19] A. Fasano, G. Woyessa, J. Janting, H. K. Rasmussen, and O. Bang, "Solution-mediated annealing of polymer optical fiber Bragg gratings at room temperature," IEEE Photonics Technology Letters, vol. 29, no. 8, pp. 687-690, 2017. [Online]. Available: http://ieeexplore.ieee.org/document/7872475/

[20] C. M. Hansen, Hansen solubility parameters. A user's handbook, 2nd ed. CRC Press, 2007.

[21] R. Inglev, J. Janting, K. Nielsen, G. Woyessa, and O. Bang, "The application of hansen solubility parameters for local etching of topas polymer optical fibers," in 26th International Conference on Optical Fiber Sensors. Optical Society of America, 2018, p. TuE66. [Online]. Available: http://www.osapublishing.org/abstract.cfm?URI=OFS-2018TuE66

[22] G. Rajan, B. Liu, Y. Luo, E. Ambikairajah, and G. D. Peng, "High sensitivity force and pressure measurements using etched singlemode polymer fiber bragg gratings," IEEE Sensors Journal, vol. 13, no. 5, pp. 1794-1800, 2013.

[23] G. Rajan, M. Noor, N. Lovell, E. Ambikaizrajah, G. Farrell, and G.D. Peng, "Polymer micro-fiber Bragg grating," Optics Letters, vol. 38, no. 17, pp. 38-41, 2013.

[24] X. Hu, C.-F. J. Pun, H.-Y. Tam, P. Mégret, and C. Caucheteur, "Highly reflective Bragg gratings in slightly etched step-index polymer optical fiber." Optics express, vol. 22, no. 15, pp. 18 807-17, 2014. [Online]. Available: http://www.ncbi.nlm.nih.gov/pubmed/25089498

[25] D. F. Merchant, P. J. Scully, and N. F. Schmitt, "Chemical tapering of polymer optical fibre," Sensors and Actuators, A: Physical, vol. 76, no. 1-3, pp. 365-371, 1999.

[26] M. Nielsen and N. Mortensen, "Photonic crystal fiber design based on the V-parameter." Optics express, vol. 11, no. 21, pp. 2762-2768, 2003.

[27] A. Stefani, K. Nielsen, H. K. Rasmussen, and O. Bang, "Cleaving of topas and pmma microstructured polymer optical fibers: Core-shift and statistical quality optimization," Optics Communications, vol. 285, no. 7, pp. 1825-1833, 2012.

[28] A. Stefani, W. Yuan, C. Markos, and O. Bang, "Narrow bandwidth 850nm fiber bragg gratings in few-mode polymer optical fibers," I E E E Photonics Technology Letters, vol. 23, no. 10, pp. 660-662, 2011.

[29] I.-L. Bundalo, K. Nielsen, C. Markos, and O. Bang, "Bragg grating writing in PMMA microstructured polymer optical fibers in less than 7 minutes." Optics Express, vol. 22, no. 5, pp. 5270-6, 2014. [Online]. Available: http://www.ncbi.nlm.nih.gov/pubmed/24663867

[30] A. Pospori, C. A. F. Marques, O. Bang, D. J. Webb, and P. André, "Polymer optical fiber bragg grating inscription with a single uv laser pulse," Opt. Express, vol. 25, no. 8, pp. 9028-9038, Apr 2017. [Online]. Available: http://www.opticsexpress.org/abstract.cfm?URI=oe25-8-9028

[31] C. A. Marques, R. Min, A. Leal, P. Antunes, A. Fasano, G. Woyessa, K. Nielsen, H. K. Rasmussen, B. Ortega, and O. Bang, "Fast and stable 
gratings inscription in pofs made of different materials with pulsed 248 nm krf laser," Optics Express, vol. 26, no. 2, pp. 2013-2022, 2018.

[32] D. Ganziy, O. Jespersen, G. Woyessa, B. Rose, and O. Bang, "Dynamic gate algorithm for multimode fiber Bragg grating sensor systems," Applied Optics, vol. 54, no. 18, p. 5657, 2015. [Online]. Available: https://www.osapublishing.org/abstract.cfm?URI=ao-54-18-5657

[33] K. Ueberreiter, "The solution process." in Diffusion in polymers., J. Crank and G. S. Park, Eds. Academic Press, 1968, pp. 219-257.

[34] J. K. M. Pedersen, J. Janting, G. Woyessa, K. Nielsen, and O. Bang, "All-Polymer fiber Bragg grating based $\mathrm{pH}$ sensor," in 26th International Conference on Optical Fiber Sensors. Optical Society of America, 2018, p. ThE52. [Online]. Available: http://www.osapublishing.org/abstract.cfm?URI=OFS-2018-ThE52

[35] C. sub Park, Y. Han, K.-I. Joo, Y. W. Lee, S.-W. Kang, and H.-R. Kim, "Optical detection of volatile organic compounds using selective tensile effects of a polymer-coated fiber bragg grating," Opt. Express, vol. 18, no. 24, pp. 24753-24761, Nov 2010. [Online]. Available: http://www.opticsexpress.org/abstract.cfm?URI=oe-18-24-24753

[36] A. Taslc, B. D. Djordjevlč, D. K. Grozdanlč, and M. Radojkovlč, "Use of Mixing Rules In Predicting Refractive Indexes and Specific Refractivities for Some Binary Liquid Mixtures," Journal of Chemical and Engineering Data, vol. 37, no. 3, pp. 310-313, 1992.

[37] M. N. Polyanskiy, "Refractive index database," https://refractiveindex. info, accessed on 2018-11-20.

[38] P. Stajanca, O. Cetinkaya, M. Schukar, P. Mergo, D. J. Webb, and K. Krebber, "Molecular alignment relaxation in polymer optical fibers for sensing applications," Optical Fiber Technology, vol. 28, pp. $11-17,2016$. [Online]. Available: http://www.sciencedirect.com/science/article/pii/S1068520015001716

[39] F. Knap, "Effect of residual stresses in wire drawing," Wire World International, vol. 26, no. 6, pp. 253-255, 1984.

[40] W. Hermann, M. Hutjens, and D. U. Wiechert, "Stress in optical waveguides. 3: Stress induced index change," Applied Optics, vol. 28, no. 11, pp. 1980-1983, 1989.

[41] W. Young, Roark's Formulas for Stress \& Strain. McGraw-Hill International Editions, 1989.

[42] D. Van Krevelen and K. Te Nijenhuis, Mechanical Properties of Solid Polymers. Elsevier B.V., 2009. [Online]. Available: http://linkinghub.elsevier.com/retrieve/pii/B9780080548197000133

[43] R. Francesconi and S. Ottani, "Correlation of density and refraction index for liquid binary mixtures containing polyglycols. Use of the group contributions in the Lorentz-Lorenz, Gladstone-Dale and Vogel equations to evaluate the density of mixtures," Journal of Molecular Liquids, vol. 133, no. 1-3, pp. 125-133, 2007.

[44] J. Roths and F. Jülich, "Determination of strain sensitivity of free fiber bragg gratings," Proceedings of Spie - the International Society for Optical Engineering, vol. 7003, p. 700308, 2008.

[45] J. H. Lamble and E. S. Dahmouch, "Photoelastic properties of plasticised polymethyl methacrylate in the glassy state," British Journal of Applied Physics, vol. 9, no. 10, pp. 388-391, 1958.

[46] B. A. Miller-Chou and J. L. Koenig, "A review of polymer dissolution," Progress in Polymer Science (Oxford), vol. 28, no. 8, pp. 1223-1270, 2003.

[47] B. Narasimhan and N. A. Peppas, "The Physics of Polymer Dissolution: Modeling Approaches and Experimental Behavior," in Advances in Polymer Science, Vol. 128, S. Edwards, Ed. Springer-Verlag Berlin Heidelberg, 1997, pp. 158-207.

[48] B. Narasimhan, "Mathematical models describing polymer dissolution: Consequences for drug delivery," Advanced Drug Delivery Reviews, vol. 48, no. 2-3, pp. 195-210, 2001.

[49] I.-L. Bundalo, K. Nielsen, G. Woyessa, and O. Bang, "Long-term strain response of polymer optical fiber FBG sensors," Optical Materials Express, vol. 7, no. 3, pp. 967-976, 2017.

[50] U. W. Gedde, Chain Orientation. Dordrecht: Springer Netherlands, 1999, pp. 199-216. [Online]. Available: https://doi.org/10.1007/978-94011-0543-9_9 